\title{
Circulating tumor cells and serum levels of MMP-2, MMP-9 and VEGF as markers of the metastatic process in patients with high risk of metastatic progression
}

\author{
Marketa Skerenovaa ${ }^{\mathrm{a}}$, Veronika Mikulova ${ }^{\mathrm{a}}$, Otakar Capoun', Tomas Zima $^{\mathrm{a}}$, Petra Tesarova ${ }^{\mathrm{b}}$
}

Background and Aims. Metastases are a severe complication in cancer patients and biomarkers predicting their progression are still lacking for specific groups of patients. HER2 positive breast cancer (HER2 BC) patients on trastuzumab therapy are at risk of the development of unpredictable and often fatal central nervous system (CNS) metastases and castration resistant prostate cancer (CRPC) patients urgently need a marker of disease progression during therapy. Proposed metastatic markers: circulating tumor cells (CTC), serum levels of matrix metalloproteinase 2 (MMP-2), 9 (MMP-9) and vascular endothelial growth factor (VEGF) were prospectively studied to confirm their utility in these two narrowly defined groups of cancer patients.

Patients and Methods. The groups comprised 44 advanced HER2 BC, 24 CRPC patients and 42 healthy controls. An immunomagnetic separation method followed by PCR and electrophoretic detection (AdnaGen, Germany) were used for CTC determination. Serum marker levels were determined by the ELISAs (R\&D System, USA).

Results. MMP-2 serum level was significantly higher in HER2 BC patients who developed CNS metastases, especially if there were also bone metastases. CTCs were a negative predictive marker for overall survival in HER2 BC patients. MMP-9 serum level was significantly higher in CRPC patients in whom disease progression occurred. CTC vanished from the blood of most of the CRPC patients (from 88\% to 37\%) during chemotherapy.

Conclusion. MMP-2 serum level and CTCs show the potential to predict CNS metastases and overall survival in BC patients. CTCs and MMP-9 serum level could be a promising therapy response marker in CRPC patients.

Key words: cancer biomarkers, circulating tumor cells, matrix metalloproteinases, vascular endothelial growth factor, breast cancers, prostate cancer

Received: December 13, 2016; Accepted with revision: April 28, 2017; Available online: May 16, 2017

https://doi.org/10.5507/bp.2017.022

aInstitute of Medical Biochemistry and Laboratory Diagnostics, General University Hospital in Prague and First Faculty of Medicine, Charles University, Prague, Czech Republic

${ }^{b}$ Department of Oncology, General University Hospital in Prague and First Faculty of Medicine, Charles University, Prague, Czech Republic 'Department of Urology, General University Hospital in Prague and First Faculty of Medicine, Charles University, Prague, Czech Republic Coresponding author: Marketa Skerenova, e-mail:jancikova.market@gmail.com

\section{INTRODUCTION}

Activation of tumor cell invasiveness and subsequent angiogenesis required for metastatic growth are crucial hallmarks of cancer cells ${ }^{1}$. Metastases formation is mediated by circulating tumor cells (CTCs) i.e. cells that have escaped from the primary tumor. Several studies have proven that CTCs can serve as a powerful marker in advanced breast and prostate cancer ${ }^{2-6}$. However, the escape of tumor cells from the primary tumor, their entry into the circulation and subsequent metastasis is a complex process. Gelatinases, also known as matrix metalloproteinase 2 (MMP-2) and 9 (MMP-9), are important factors in this process. Gelatinases have been widely studied as potential cancer markers for their ability to degrade extracellular matrix and basement membrane ${ }^{7,8}$. They help tumor cells enter the circulation and they may also support their extravasation and metastasis ${ }^{911}$. Moreover, MMP-9 is closely linked with angiogenesis which is essential for tumor and metastasis growth ${ }^{12}$. One way by which MMP-9 can modulate angiogenesis is through vascular endothelial growth factor (VEGF) $\left(\right.$ ref. $\left.{ }^{11}\right)$. VEGF participates in embryogenesis, organ development and wound healing ${ }^{13}$. The involvement of VEGF in tumor cell invasion and survival has also been suggested ${ }^{14}$. However, VEGF is mainly studied in connection with tumor-vessel formation. It is considered to be the main angiogenic factor enabling tumor and metastasis growth.

Higher VEGF expression in tumor cells correlates with poorer disease prognosis ${ }^{15,16}$. The ability of VEGF to increase the permeability of vessels may facilitate tumor cell entry into the circulation as well as extravasation at the place of a new metastasis ${ }^{17-20}$.

We wanted to explore the predictive potential of the chosen markers in two well-defined groups of advanced cancer patients in which a metastatic process play a crucial role and which urgently need a predictive biomarker. Patients with human epidermal growth factor receptor 2 positive breast cancer (HER2 BC) receiving trastuzumab therapy are at increased risk of central nervous system (CNS) metastasis ${ }^{21,22}$. The aim of this study was to determine the relationship between the development of metastases and metastatic serum marker levels/ CTCs. Most castration resistant prostate cancer (CRPC) patients 
already have multiple metastases. A prostate-specific antigen (PSA) decline of $>30 \%$ may be associated with therapy efficacy, although the results of studies are conflicting ${ }^{23}$. The introduction of additional markers should help the clinician to recognize those patients who would benefit from chemotherapy from those who would not. We would like to study the applicability of the proposed metastatic markers to these unanswered clinical questions.

Many different studies have investigated the serum levels of MMP-2, MMP-9 and VEGF in cancer patients with different and sometimes contradictory results ${ }^{8,24-32}$. We wanted to incorporate these arguable markers into specific clinical events of two narrowly defined groups of cancer patients to prove or disprove their clinical utility.

\section{MATERIALS AND METHODS}

\section{Patient characteristics}

Two well-defined groups of advanced cancer patients endangered by metastatic progression were prospectively monitored for metastatic markers and compared with control subjects. The groups comprised 44 patients with advanced HER2 BC, 24 patients with CRPC and 42 healthy volunteers. The study was approved by the Ethics Committee of the General University Hospital in Prague. All participants in the study signed their informed consent.

The BC patients were selected according to the following criteria: advanced breast cancer; HER2 positive status; and trastuzumab or lapatinib palliative treatment. All of these patients were at increased risk of CNS metastases although the duration of treatment differed. The median duration of therapy was 30 months (from 3 to 83 ). For this reason it was impossible to take samples in the same therapy cycle for every patient. Blood samples were taken once in the course of treatment preceding trastuzumab or oral lapatinib in the therapy cycle following the patient's enrolment in the study.

The prostate cancer patients' enrolment was based on castration resistant stage criteria according to the European Association of Urology guidelines ${ }^{33}$. All the CRPC patients were enrolled at the time of CRPC diagnosis. For this reason, blood was sampled twice, at the time of indication to docetaxel therapy (the first measurement) and in the course of the therapy after the third cycle of chemotherapy (the second measurement), to evaluate the therapy response.

The control group comprised 42 healthy volunteer (21 men and 21 women). The median age of the control group was 41 (from 23 to 63) years. The median age of men and women was 42 (from 23 to 53) and 40 (from 24 to 63) years respectively. CTC presence was not investigated in the blood of the healthy controls. It was presumed, based on the literature, that CTCs would not be present in healthy people 5,34,35 $^{5}$

\section{Methods}

Whole blood for CTC analysis and serum for the determination of serum markers were collected from each patient. The serum was divided into aliquots and stored at $-20{ }^{\circ} \mathrm{C}$. The serum levels of MMP-2, MMP-9 and VEGF were determined by Quantikine ${ }^{\circledR}$ ELISA Human MMP-2, MMP-9 and VEGF respectively (R\&D Systems, USA). CTC presence was determined by the AdnaTestBreast/ Prostate Cancer Select/Detect (AdnaGen, Germany). CTCs were enriched by an immunomagnetic separation from the $5 \mathrm{~mL}$ of whole blood. The enriched cells were washed three times and lysed. mRNA from the lysate was isolated by the immunomagnetic separation and transcribed to the cDNA by a reverse transcription (Qiagen, Germany). Afterwards, a Multiplex-PCR and onchip capillary electrophoresis (2100 Bioanalyzer, Agilent, USA) were used to check the presence of PCR products originated from three tumor-associated and one control gene transcripts (AdnaGen, Germany; Qiagen, Germany). The monitored PCR products were HER2, Mucin and Epithelial cell adhesion molecule (EpCAM) in breast cancer and epidermal growth factor receptor (EGFR), PSA and prostate-specific membrane antigen (PSMA) in prostate cancer patients. Actin was used as a control fragment in both cases. According to manufacturer, the detection of at least one of the tumor-associated PCR products at a concentration higher than $0.15 \mathrm{ng} / \mathrm{mL}$ proved the patient CTC positive.

\section{Statistical analysis}

Collected data were analyzed using SAS software (SAS Institute Inc., Cary, NC, USA). Basic statistical data were computed for the whole study group. A Wilcoxon test or Kruskal-Wallis test were used to compare the differences in variables among defined groups. The relations between the variables were examined using Spearman's correlation coefficients. The optimal cut-offs were determined both by a receiver-operating characteristic (ROC) analysis and an odds ratio (risk evaluation). The differences between variables were tested using a Chi-squared test or Fisher's exact test. Overall survival (OS) was determined using Kaplan-Meier survival curves. The impact of the monitored factors on OS was tested using the log-rank test and Cox regression analysis (Hazard Ratio). The statistical significance $(P)$ was set to 0.05 .

\section{RESULTS}

\section{Characterization of study groups}

The study group characteristics are summarized in Table 1. In the HER2 BC group, CTC presence was determined in $29(66 \%)$ of the patients. Thirteen patients were enrolled in a small preliminary study where only serum markers were determined and two samples were unevaluable. The performance status of patients was 0-1. Twelve patients in the study developed CNS metastases, three patients before their enrolment and nine during the follow-up period. The time between blood sampling and CNS metastases detection varied from 1 to 20 months. Fourteen patients (32\%) died during the project.

In the CRPC group, CTCs were determined in 24 $(100 \%)$ and $21(88 \%)$ of the patients in the first and 
Table 1. Study group characteristics.

\begin{tabular}{|c|c|c|}
\hline Variable & $\mathrm{n}$ & $\%$ \\
\hline All patients & 44 & $100 \%$ \\
\hline Median age (range) & $53(33-72)$ & \\
\hline Median follow-up & 3 years 6 months & \\
\hline \multicolumn{3}{|c|}{ Stadium of $\mathrm{BC}$ at the time of diagnosis } \\
\hline Localized & 6 & $14 \%$ \\
\hline Locally advanced & 21 & $48 \%$ \\
\hline Metastatic & 17 & $39 \%$ \\
\hline Unknown & 1 & $2 \%$ \\
\hline \multicolumn{3}{|l|}{ Best response } \\
\hline Complete response & 9 & $20 \%$ \\
\hline Partial response & 7 & $16 \%$ \\
\hline Stable disease & 13 & $30 \%$ \\
\hline Progressive disease & 15 & $34 \%$ \\
\hline \multicolumn{3}{|l|}{ Metastases* } \\
\hline CNS & 12 & $27 \%$ \\
\hline Bone & 12 & $27 \%$ \\
\hline Other & 20 & $45 \%$ \\
\hline None & 7 & $16 \%$ \\
\hline \multicolumn{3}{|l|}{ Lapatinib therapy } \\
\hline Yes & 8 & $18 \%$ \\
\hline No & 36 & $82 \%$ \\
\hline Unknown & 1 & $2 \%$ \\
\hline \multicolumn{3}{|l|}{ Hormone receptor status* } \\
\hline ER & 16 & $36 \%$ \\
\hline PR & 16 & $36 \%$ \\
\hline Unknown & 1 & $2 \%$ \\
\hline \multicolumn{3}{|l|}{ CTC status } \\
\hline Positive & 5 & $11 \%$ \\
\hline Negative & 24 & $55 \%$ \\
\hline Unknown & 15 & $34 \%$ \\
\hline
\end{tabular}

* presence of more than one positive characteristic in one patient is possible a) HER2 positive breast cancer

\section{b) Castration resistant prostate cancer}

\begin{tabular}{lcc}
\hline Variable & $\mathrm{n}$ & $\%$ \\
\hline All patients & 24 & $100 \%$ \\
Median age (range) & $70(54-82)$ & \\
Median follow-up & 1 years 4 months & \\
\hline
\end{tabular}

Stadium of PC at the time of diagnosis

$\begin{array}{lrr}\text { Localized } & 15 & 63 \% \\ \text { Locally advanced } & 3 & 13 \% \\ \text { Metastatic } & 6 & 25 \%\end{array}$

\begin{tabular}{lll}
\hline Best response & & \\
\hline Complete response & 0 & $33 \%$ \\
Partial response & 8 & $33 \%$ \\
Stable disease & 9 & $38 \%$ \\
Progressive disease & 3 & $13 \%$ \\
Unknown & 4 & $17 \%$ \\
\hline Metastases & & \\
\hline Bone & 19 & $79 \%$ \\
None & 3 & $13 \%$ \\
Unknown & 2 & $8 \%$ \\
& & \\
\hline
\end{tabular}

\begin{tabular}{lrr}
\hline Previous therapy & & \\
\hline Radical prostatectomy & 6 & $24 \%$ \\
Radiotherapy & 6 & $24 \%$ \\
None & 12 & $52 \%$ \\
\hline Gleason score & & \\
\hline $6-7$ & 14 & $58 \%$ \\
$8-10$ & 8 & $33 \%$ \\
Unknown & 2 & $8 \%$ \\
\hline
\end{tabular}

CTC status before docetaxel therapy

$\begin{array}{lrr}\text { Positive } & 21 & 88 \% \\ \text { Negative } & 3 & 13 \%\end{array}$

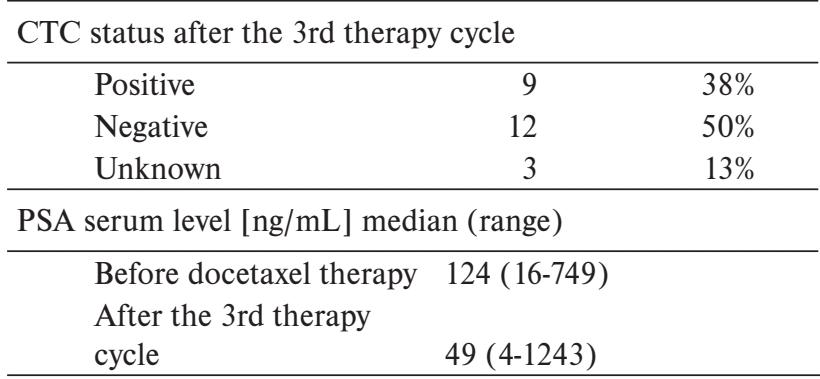

second measurements respectively. Two patients did not participate in the second measurement and the CTC determination failed in one case. The performance status of the patients at the time of blood taking ranged from 0 to 2 . Fifteen patients $(63 \%)$ died during the project.

\section{Serum marker levels in HER2 BC and CRPC patients in comparison with the control group}

Since no statistical significant differences were found in the serum marker levels between men and women the control group was not divided according to sex. Similarly, no correlation of serum markers with age was found in any studied group. The only exception was MMP-9 serum level in the control group which showed a weak positive correlation with age (correlation coefficient $=0.375 ; P=0.016$ ). The serum marker levels are presented in Table 2.

In the HER2 BC group, serum marker levels were measured in 42 (96\%) patients; two serum samples were not measurable because of haemolysis. In the CRPC group, serum marker levels were determined in $17(71 \%)$ and 20 
Table 2. Serum marker levels in the HER2 BC patiens, CRPC patients and control group.

\begin{tabular}{lccc}
\hline Serum marker levels & $\begin{array}{c}\text { MMP2 Median } \\
(\mathrm{min}-\mathrm{max}) \\
{[\mathrm{ng} / \mathrm{mL}]}\end{array}$ & $\begin{array}{c}\text { MMP9 Median } \\
(\mathrm{min}-\mathrm{max}) \\
{[\mathrm{ng} / \mathrm{mL}]}\end{array}$ & $\begin{array}{c}\text { VEGF Median } \\
(\mathrm{min}-\mathrm{max}) \\
{[\mathrm{pg} / \mathrm{mL}]}\end{array}$ \\
\hline Control group-women $(\mathrm{N}=21)$ & 193 & 650 & 237 \\
& $(163-262)$ & $(3-1113)$ & $(102-636)$ \\
Control group-men $(\mathrm{N}=21)$ & 202 & $(3-912)$ & 239 \\
& $(145-319)$ & 597 & $(19-589)$ \\
Control group $(\mathrm{N}=42)$ & 201 & $(3-1113)$ & 238 \\
& $(145-319)$ & 294 & $(19-636)$ \\
HER2 BC $\left(\mathrm{N}=42^{\dagger}\right)$ & $249^{* *}$ & $(65-1070)$ & 245 \\
CRPC First measurement $\left(\mathrm{N}=17^{\dagger}\right)$ & $(143-407)$ & 385 & $(0-2800)$ \\
CRPC Second measurement $\left(\mathrm{N}=20^{\dagger}\right)$ & $243^{*}$ & $(47-785)$ & 332 \\
& $(147-342)$ & 544 & $(125-1050)$ \\
\end{tabular}

Women and men both separately and all together.

Statistically significant differences from the control group are marked with stars $\left({ }^{*} P<0.050\right.$; $\left.{ }^{* *} P<0.001\right)$.

$\dagger$ The numbers of cases differed slightly between the groups because a few patients lacked serum marker level measurement.

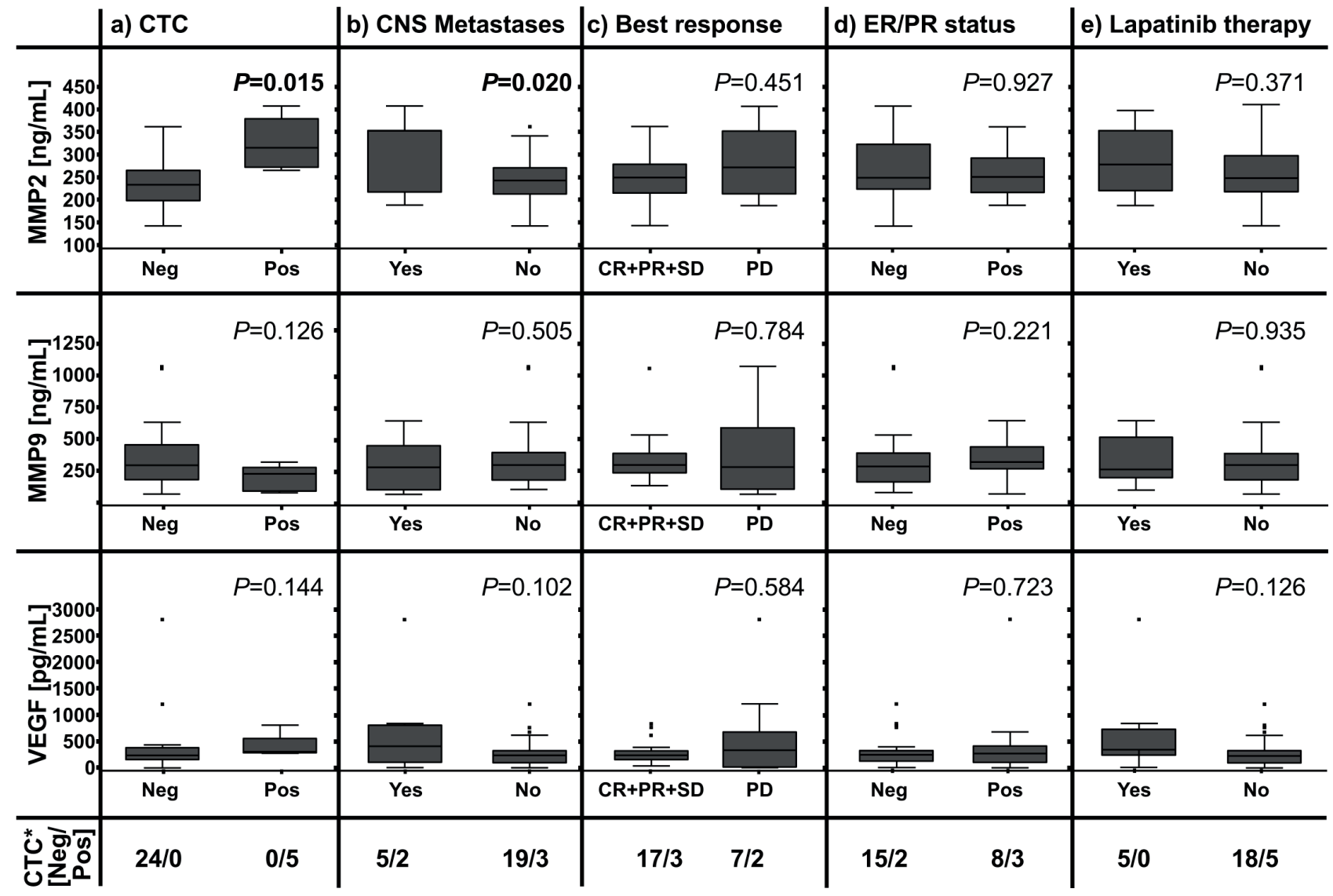

Fig. 1. The comparison of MMP-2, MMP-9 and VEGF serum levels and CTC presence in HER2 BC patients.

a) CTC negative $(\mathrm{N}=23)$ vs. CTC positive $(n=4)$

b) with ( $n=11)$ vs. without $(n=31)$ CNS metastases

c) without $(n=27)$ vs. with $(n=15)$ disease progression

d) without ( $n=24)$ vs. with $(n=17)$ primary tumor ER and/or PR positivity

e) with $(n=8)$ vs. without $(n=33)$ lapatnib therapy. Statistically significant differences are bold $(P<0.05)$

Neg-negative; Pos-positive; CNS-central nervous system; ER-oestrogen receptor positive primary tumor; PR-progesterone receptor positive primary tumor; PD-progressive disease, SD-Stable disease, PR-partial response, CR-complete response; N-number of performed serum marker measurements. *Number of CTC measurement can differ from number of serum marker measurement. 


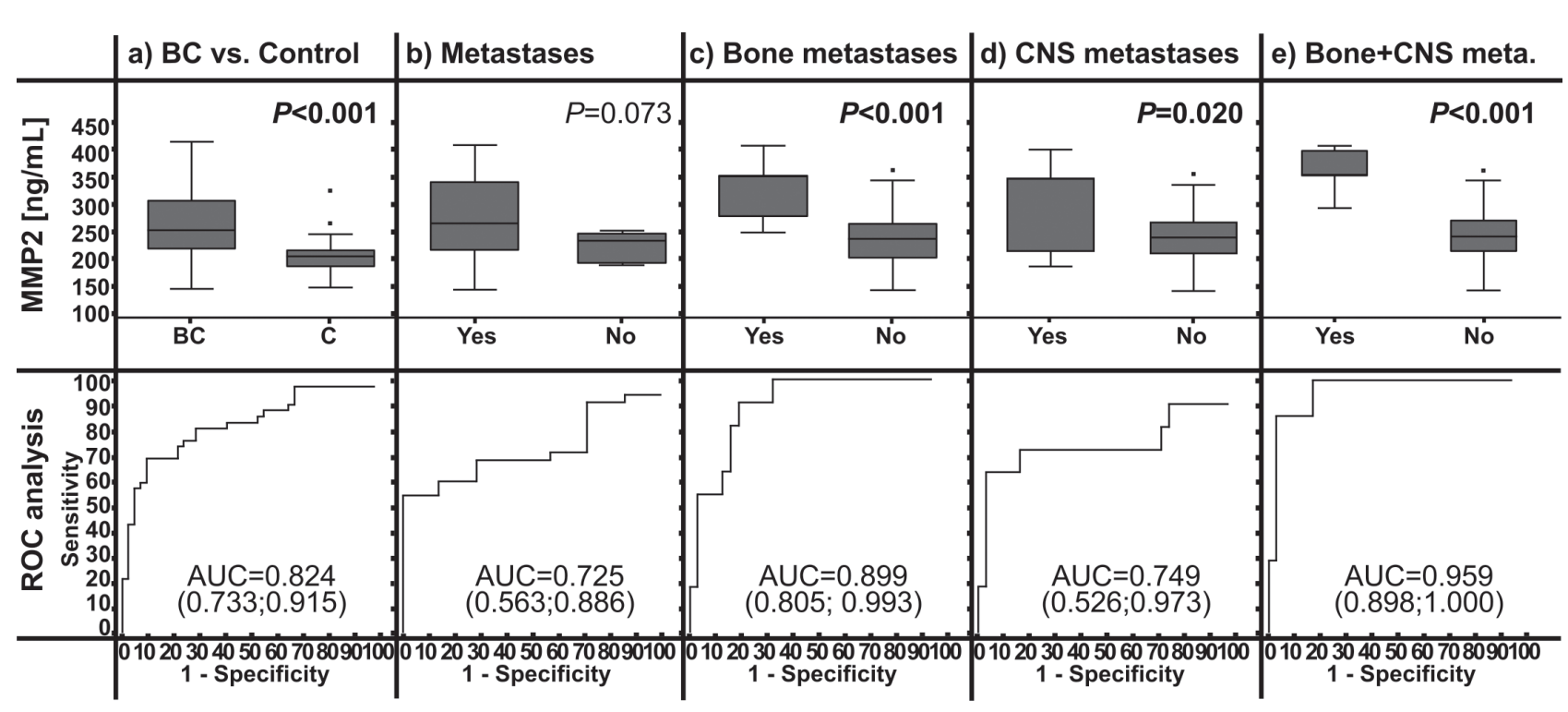

f) Summary of determined MMP2 cut-offs

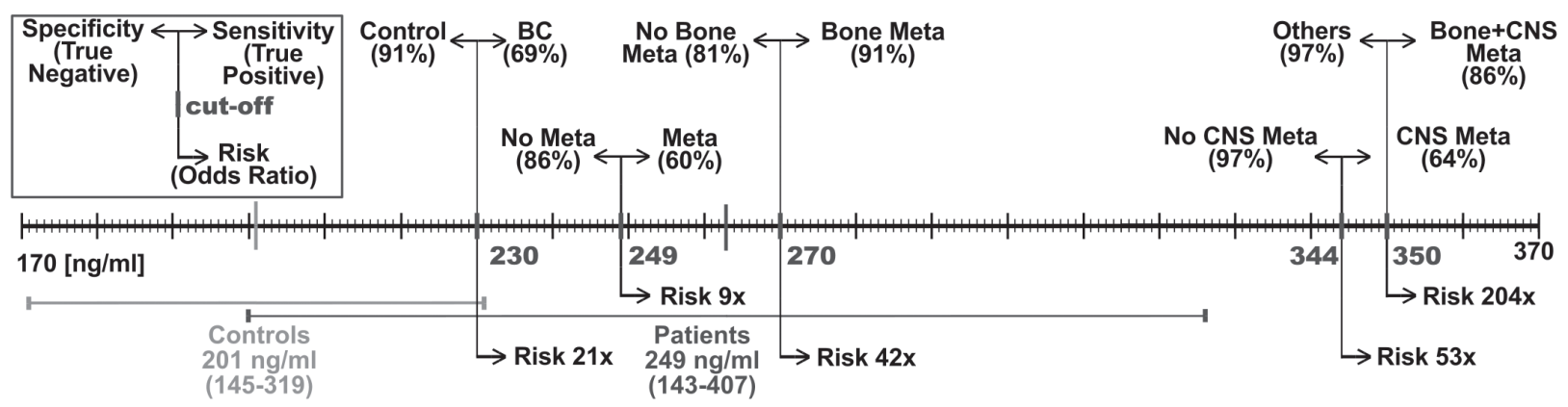

Fig. 2. Serum levels and ROC analysis of MMP-2 in the HER2 BC patients $(n=42)$.

a) vs. control group $(n=42)$

b) with $(n=35)$ vs. without $(n=7)$ metastases

c) with $(n=11)$ vs. without $(n=31)$ bone metastases

d) with ( $n=11)$ vs. without ( $n=31)$ CNS metastases

e) with bone and CNS metastases $(n=7)$ vs. other patients $(n=35)$

f) concluding diagram with the cut-offs, specificity, sensitivity and risk values for different pathologic states. Statistically significant differences are bold $(\mathrm{P}<0.05)$

BC-breast cancer; C-control group; CNS-central nervous system; Meta-metastases; AUC-area under curve; N-number of performed serum marker measurements.

(83\%) of CRPC patients in the first and second measurements respectively. The lack of serum marker measurement was caused either by the sample haemolysis or the loss of the patient during the study.

\section{Serum marker levels and CTC in HER2 positive breast cancer patients}

The results for the HER2 BC patients, divided according to monitored characteristics are presented in Fig. 1.

Although the difference in MMP-2 serum level between patients with and without metastases was not statistically significant at the 0.05 level (Fig. 2b), the MMP-2 serum level in the patients who developed CNS metastases significantly differed from those who did not (Fig. 2d). Moreover, the patients with bone metastases also showed significantly elevated MMP-2 serum levels in comparison with patients without bone metastases (Fig. 2c). In agreement with these results, the highest MMP2 serum level was measured in seven patients who developed CNS metastases and who had bone metastases (Fig. 2e).The MMP2 serum level cut-offs, specificity, sensitivity and risks determined by ROC analyses are summarized in Fig. 2f.

The CTC positive patients had worse overall survival than the CTC negative ones. However, the difference was not significant probably due to the limited number of patients and high survival rate in the HER2 BC group (Fig. 3a).

\section{Prostate cancer}

Patients who had unfavourable CTC status, those who turned or stayed CTC positive, in the second measurement had shorter overall survival. However, because of the limited number of patients the difference was not statistically significant (Fig. 3b).

No correlation between CTCs, serum markers and PSA serum level was found either pre-therapy or in the 
course of therapy or in the change in their levels between the first and the second measurements (data not shown). Moderately strong significant positive correlation was found in the MMP-2 serum levels between the first and second measurements (correlation coefficient $=0.616$; $P=0.025)$. The results for serum marker levels and CTCs in the CRPC patients, divided according to monitored clinical characteristics, are presented in Fig. 4.

\section{DISCUSSION}

To the best of our knowledge, this study is the first to focus on the joint determination of CTCs and MMP2, MMP-9 and VEGF serum levels in advanced cancer patients. We presumed that these markers could predict metastasis formation and therapy efficiency in the two well-defined groups of HER2 BC and CRPC patients at risk of metastatic progression. However the narrow specification of the groups diminished the number of patients involved in the study. Since the connection of all the monitored serum markers with the metastatic process have been claimed in many previous works and our patient groups consisted of advanced cancer patients it was surprising that only MMP-2 serum level showed significant differences between the patients and control group. The VEGF serum level of CRPC patients was also significantly higher but only in the samples taken in the course of therapy-the second measurement (Fig. 4). The pre-therapy VEGF serum level -the first measurementwas not statistically significant $(P=0.072)$. Furthermore, only MMP-2 and in one case MMP-9 showed some discriminating power to distinguish between the groups of patients with monitored clinical characteristics $(P<0.05$; Fig. 1, Fig. 4).

An elevated MMP-2 serum level in BC patients has already been connected with a poor prognosis ${ }^{26}$ and the role of MMP-2 in the development of CNS metastases has been also proposed in animal experiments ${ }^{36-38}$ According to our results, the MMP-2 serum level was significantly elevated in HER2 BC patients with bone and/or CNS metastases (Fig. 2). We found out that the MMP-2 serum level has the best predictive power for the development of CNS metastases in HER2 BC patients suffering from bone metastases. The cut-off value of $350 \mathrm{ng} / \mathrm{mL}$ determined for these patients was significantly higher than the normal MMP-2 serum levels and proved to be a strong discriminator (Fig. 2e). All these data are summarized in Fig. 2f. Since CNS metastases represent a very serious and still unpredictable complication in HER2 BC our findings warrant verification in a larger group of patients.

Despite the frequency of metastases, only five HER2 BC patients (17\%) exhibited CTC positivity in our study. This can be explained by the efficacy of HER2 targeted therapy. A similar rate of CTC positivity in HER2 positive metastatic BC patients has been reported by Cristofanlli. In common with Cristofanilli, the overall survival of the CTC positive BC patients in our study was shorter in comparison with the CTC negative group. CTCs in the patients more than doubled their risk of death. However,

\section{a) HER2 BC patients}

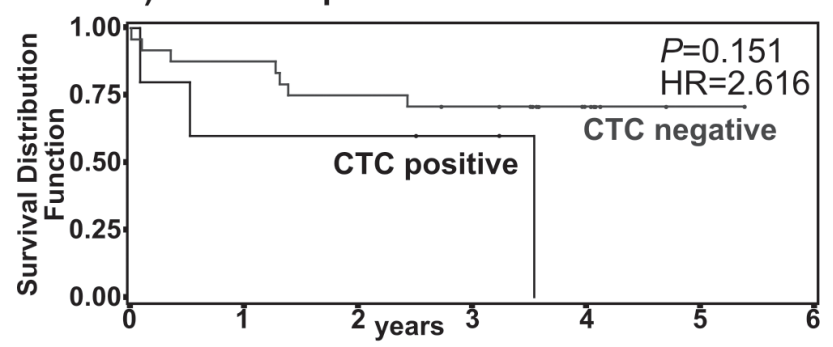

b) CRPC patients

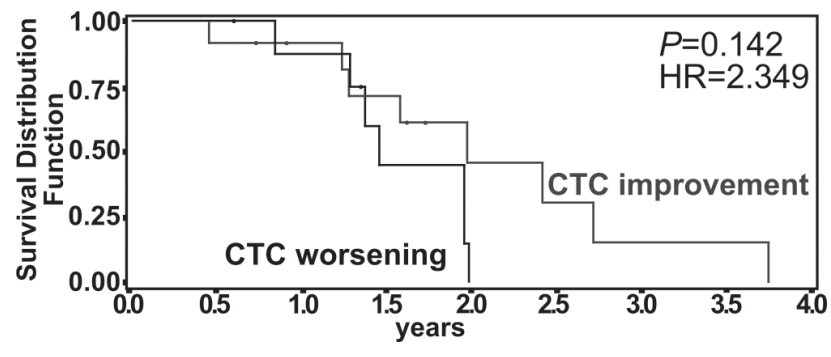

Fig. 3. Kaplan-Meier analysis of the overall survival and Hazard ration analysis (HR).

a) HER2 BC patients with vs. without CTCs

b) CRPC patients with CTC status worsening ( $\mathrm{Neg} \rightarrow \mathrm{Pos}$ or $\mathrm{Pos} \rightarrow \mathrm{Pos}$ ) vs. CTC status improvement $(\mathrm{Pos} \rightarrow \mathrm{Neg}$ or $\mathrm{Neg} \rightarrow \mathrm{Neg}$ ) in the course of therapy

the results were not statistically significant because two thirds of patients were still alive at the end of the follow-up period (Fig. 3) $\left(\right.$ ref. $\left.^{5}\right)$.

A significantly elevated MMP-2 serum level in the CTC positive patients $(P=0.015)$ was found. Moreover, 4/5 CTC positive patients had bone metastases. Despite the small number of cases, these results support other studies' findings that CTCs are more closely related to bone metastases than to the other metastatic sites ${ }^{4,39}$. Surprisingly, only 2/7 patients with bone and CNS metastases were CTC positive but four patients missed the CTC test (Fig. 1). There was no correlation between CTC positivity and CNS metastases but this may be due to the small number of CTC positive BC patients in our study. No significant differences in serum marker levels were found between patients on trastuzumab and those who were switched from trastuzumab to lapatinib therapy due to resistance to trastuzumab suggesting that the development of trastuzumab resistance causes no serum marker or CTC elevation.

In the CRPC patients, the MMP-2 serum level seems to follow the initial risk stratification of the patients according to the biopsy Gleason score. Additionally, MMP-9 serum levels measured in the course of therapy showed the predictive value for the patients' therapy response evaluation (Fig. 4). The CRPC patients with an elevated MMP-9 serum level in the second measurement had a worse overall response to docetaxel therapy $(P=0.044)$. Yet, MMP-9 serum levels in the CRPC patients did not significantly differ from the healthy controls; whereas the VEGF serum level differed significantly for CRPC patients and the control group, consistent with previous 


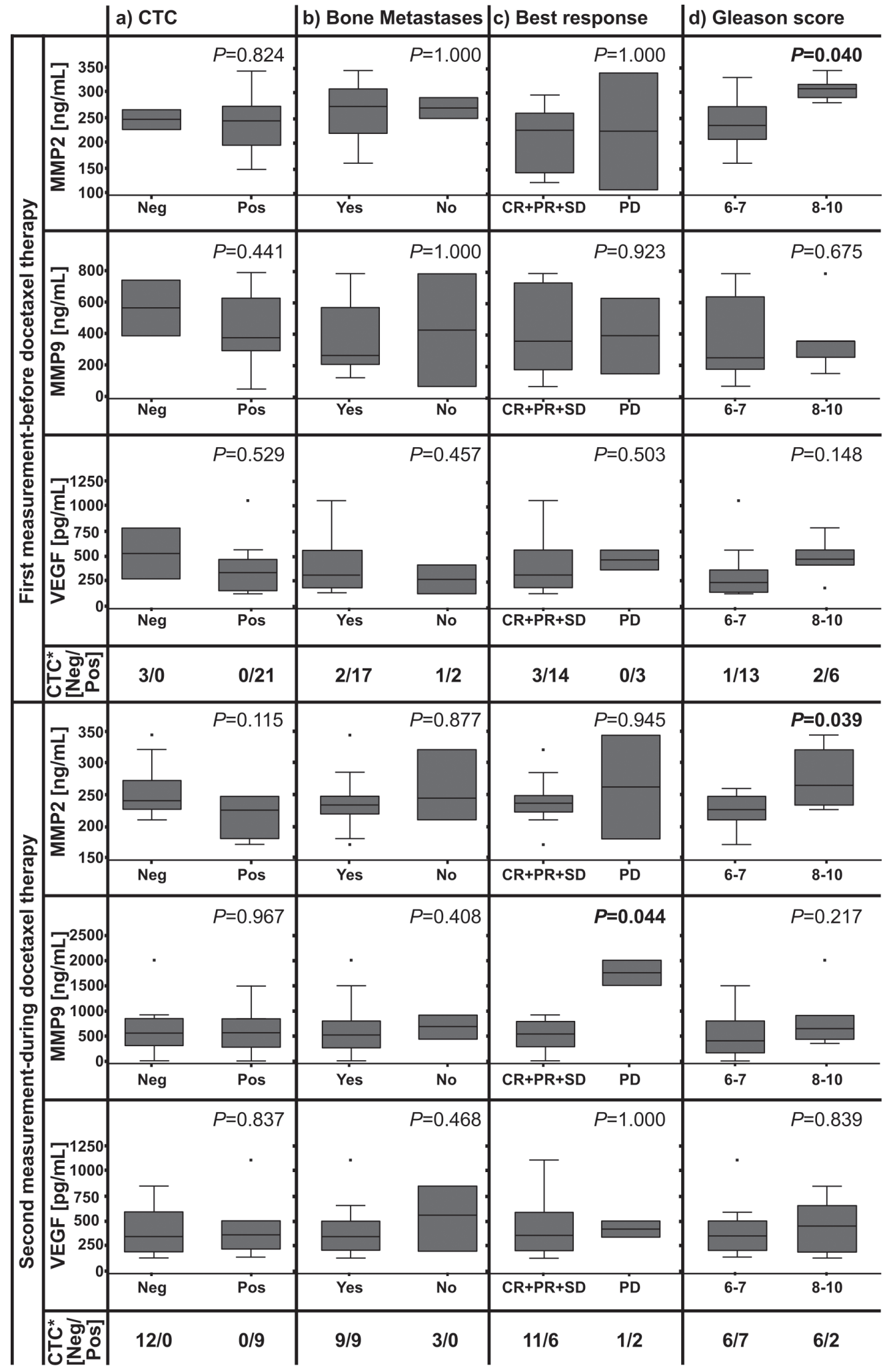

Fig. 4. The comparison of MMP-2, MMP-9 and VEGF serum levels and CTC presence in CRPC patients before and during docetaxel therapy.

a) CTC negative $\left(\mathrm{n}_{1 \mathrm{st}}=13, \mathrm{n}_{2 \mathrm{nd}}=17\right)$ vs. CTC positive $\left(\mathrm{n}_{1 \mathrm{st}}=2, \mathrm{n}_{2 \mathrm{nd}}=3\right)$

b) with $\left(\mathrm{n}_{1 \mathrm{st}}=13, \mathrm{n}_{2 \mathrm{nd}}=17\right)$ vs. without $\left(\mathrm{n}_{1 \mathrm{st}}=2, \mathrm{n}_{2 \mathrm{nd}}=3\right)$ bone metastases

c) without $\left(\mathrm{n}_{1 \mathrm{st}}=11, \mathrm{n}_{2 \mathrm{nd}}=16\right)$ vs. with $\left(\mathrm{n}_{1 \mathrm{st}}=2, \mathrm{n}_{2 \mathrm{nd}}=2\right)$ disease progression

d) with lower $\left(\mathrm{n}_{1 \mathrm{st}}=10, \mathrm{n}_{2 \mathrm{nd}}=14\right)$ vs. higher $\left(\mathrm{n}_{1 \mathrm{st}}=5, \mathrm{n}_{2 \mathrm{nd}}=6\right)$ biopsy Gleason score

Statistically significant differences are bold $(P<0.05)$.

Neg-negative; Pos-positive; PD-progressive disease, SD-Stable disease, PR-partial response, CR-complete response; $\mathrm{N}_{1 \mathrm{st}}-\mathrm{N}$-number of performed serum marker measurements before the therapy; $\mathrm{N}_{2 \text { nd }}-\mathrm{N}$-number of performed serum marker measurements during the therapy *Number of CTC measurement can differ from number of serum marker measurement. 
findings ${ }^{40}$, but failed to distinguish between the CRPC patient groups divided according to the various clinical characteristics (Table 1, Fig. 4). In contrast with the HER2 BC patients, bone metastases seem to have had no impact on the serum marker levels in the CRPC patients. Since the MMP-2 serum level has been shown by Gohji to be elevated in the PC patients with bone metastases, our results may be influenced by the small number of CRPC patients without bone metastases in our study group ${ }^{27}$. The percentage of CTC positive CRPC patients decreased during the therapy from $88 \%$ to $37 \%$ (Fig. 4). Although the patients who stayed or became CTC positive during treatment had shorter overall survival and twice the risk of death, the difference was not statistically significant (Fig. 3).

The weak points of our study were limited numbers of patients and a younger control group but, gelatinases

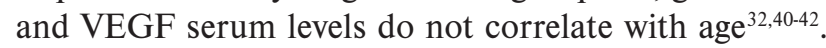
Hence age is probably not important. In this study, only the MMP-9 serum level in the control group showed a weak positive correlation with age (correlation coefficient=0.375; $P=0.016$ ). Consistent with other studies, there were no significant differences in serum marker levels between men and women in the control group ${ }^{29,41}$.

\section{CONCLUSION}

We can conclude that i) MMP-2 serum levels are significantly higher in HER2 BC patients with CNS metastases; ii) the power of MMP-2 serum level to predict CNS metastases is strongest in patients with bone metastases; iii) elevated MMP-2 levels and CTCs seem to be connected with bone metastases in HER2 BC patients; iv) CTCs are found only in small percentage (17\%) of HER2 BC patients treated with trastuzumab; v) CTCs are linked to shorter overall survival in HER2 BC patients; vi) MMP-9 serum levels are significantly higher in CRPC patients during disease progression; vii) the disappearance of CTCs from the blood of CRPC patients during therapy is connected with longer overall survival; viii) the wide range of the MMP-9 and VEGF serum levels are an unfavourable parameter for their use as clinical markers. These conclusions warrant verification in a larger study.

Acknowledgement: The authors thank MUDr. Viktor Soukup PhD. and MUDr. Hana Honová for their help with both patient enrolment and sample collection. We would like to thank Ing. Stanislav Kormunda for the statistical analysis. This work was supported by a student research grant from the Grant Agency of Charles University (GAUK 539512), by a research grant from the Internal Grant Agency of the Ministry of Health, Czech Republic (IGA MZ NT 12205-5), by a Czech Ministry of Health project for the conceptual development of research, organized under the General University Hospital in Prague (RVO-VFN-64165) and by a program of scientific branch progress (Progres Q25/LF1).

Author contributions: MJ: study conception and design, acquisition of data, data analysis and interpretation, manuscript drafting; VM: study conception and design, data analysis and interpretation, critical revision; OC: acquisition of data, critical revision; TZ: critical revision; PT: acquisition of data, critical revision

Conflict of interest statement: The authors state that there are no conflicts of interest regarding the publication of this article.

\section{REFERENCES}

1. Hanahan D, Weinberg RA. Hallmarks of Cancer:The Next Generation. Cell 2011;144(5):646-74.

2. Murray NP, Reyes E, Orellana N, Fuentealba C, Bádinez L, Olivares R, Porcell J, Dueñas R. Secondary Circulating Prostate Cells Predict Biochemical Failure in Prostate Cancer Patients after Radical Prostatectomy and without Evidence of Disease. Sci World J 2013;2013:1-7.

3. Thalgott M, Rack B, Maurer T, Souvatzoglou M, Eiber M, KreßV, Heck MM, Andergassen U, Nawroth R, Gschwend JE, Retz M. Detection of circulating tumor cells in different stages of prostate cancer. J Cancer Res Clin Oncol 2013;139(5):755-63.

4. Peeters DJE, van Dam P-J, Van den Eynden GGM, Rutten A, Wuyts $\mathrm{H}$, Pouillon L, Peeters M, Pauwels P, Van Laere SJ, van Dam P a, Vermeulen PB, Dirix LY. Detection and prognostic significance of circulating tumour cells in patients with metastatic breast cancer according to immunohistochemical subtypes. Br J Cancer 2014;110(2):375-83.

5. Cristofanilli M, Budd GT, Ellis MJ, Stopeck A, Matera J, Miller MC, Reuben JM, Doyle G V, Allard WJ, Terstappen LWMM, Hayes DF. Circulating tumor cells, disease progression, and survival in metastatic breast cancer. N Engl J Med 2004;351(8):781-91.

6. Lianidou ES, Markou A. Circulating tumor cells as emerging tumor biomarkers in breast cancer. Clin Chem Lab Med 2011;49(10):157990.

7. Björklund M, Koivunen E. Gelatinase-mediated migration and invasion of cancer cells. Biochim Biophys Acta 2005;1755(1):37-69.

8. Deryugina El, Quigley JP. Matrix metalloproteinases and tumor metastasis. Cancer Metastasis Rev 2006;25(1):9-34.

9. Packard BZ, Artym V V, Komoriya A, Yamada KM. Direct visualization of protease activity on cells migrating in three-dimensions. Matrix Biol 2009;28(1):3-10.

10. Agrawal S, Anderson P, Durbeej $M$, van Rooijen N, Ivars $F$ Opdenakker G, Sorokin LM. Dystroglycan is selectively cleaved at the parenchymal basement membrane at sites of leukocyte extravasation in experimental autoimmune encephalomyelitis. J Exp Med 2006;203(4):1007-19.

11. Kessenbrock K, Plaks V, Werb Z. Matrix metalloproteinases: regulators of the tumor microenvironment. Cell 2010;141(1):52-67.

12. Bergers G, Brekken R, McMahon G, Vu TH, Itoh T, Tamaki K, Tanzawa K, Thorpe P, Itohara S, Werb Z, Hanahan D. Matrix metalloproteinase-9 triggers the angiogenic switch during carcinogenesis. Nat Cell Biol 2000;2(10):737-44.

13. Ferrara N, Davis-Smyth T. The biology of vascular endothelial growth factor. Endocr Rev 1997;18(1):4-25.

14. Perrot-Applanat M, Di Benedetto $M$. Autocrine functions of VEGF in breast tumor cells: adhesion, survival, migration and invasion. Cell Adh Migr 2012;6(6):547-53.

15. Hicklin DJ, Ellis LM. Role of the vascular endothelial growth factor pathway in tumor growth and angiogenesis. J Clin Oncol 2005;23(5):1011-27.

16. Nieves BJ, D'Amore $P$ a, Bryan $B$ a. The function of vascular endothelial growth factor. Biofactors 2009;35(4):332-7.

17. Zhang Y, Ma Q, Liu T, Ke S, Jiang K, Wen Y, Ma B, Zhou Y, Fan Q, Qiu X. Tumor self-seeding by circulating tumor cells in nude mouse models of human osteosarcoma and a preliminary study of its mechanisms. J Cancer Res Clin Oncol 2014;140(2):329-40.

18. Kim M, Oskarsson T, Acharyya S, Nguyen DX, Zhang XH-F, Norton $\mathrm{L}$, Massagué J. Tumor self-seeding by circulating cancer cells. Cell 2009;139(7):1315-26.

19. Bates DO. Vascular endothelial growth factors and vascular permeability. Cardiovasc Res 2010;87(2):262-71. 
20. Roskoski R. Vascular endothelial growth factor (VEGF) signaling in tumor progression. Crit Rev Oncol Hematol 2007;62(3):179-213.

21. Lin NU, Bellon JR, Winer EP. CNS metastases in breast cancer. J Clin Oncol 2004;22(17):3608-17.

22. Serpico D, Porcu L, Tessari A, Gevorgyan A, Bregni G, Galli G, de Braud F, Torri V, Di Cosimo S. Disease progression pattern in metastatic breast cancer patients treated with anti-HER2 therapies. Clin Transl Oncol 2015;17(7):530-8.

23. Heidenreich A, Bastian PJ, Bellmunt J, Bolla M, Joniau S, van der Kwast T, Mason M, Matveev V, Wiegel T, Zattoni F, Mottet N. EAU guidelines on prostate cancer. Part II: Treatment of advanced, relapsing, and castration-resistant prostate cancer. Eur Urol 2014;65(2):467-79.

24. Turpeenniemi-Hujanen T. Gelatinases (MMP-2 and -9) and their natural inhibitors as prognostic indicators in solid cancers. Biochimie 2005;87(3-4):287-97.

25. Kuvaja $P$, Talvensaari-Mattila $A$, Pääkkö $P$, Turpeenniemi-Hujanen T. Low serum level of pro-matrix metalloproteinase 2 correlates with aggressive behavior in breast carcinoma. Hum Pathol 2006;37(10):1316-23

26. Leppa S. A High Serum Matrix Metalloproteinase-2 Level Is Associated with an Adverse Prognosis in Node-Positive Breast Carcinoma. Clin Cancer Res 2004;10(3):1057-63.

27. Gohji K, Fujimoto N, Hara I, Fujii A, Gotoh A, Okada H, Arakawa S, Kitazawa S, Miyake H, Kamidono S, Nakajima M. Serum matrix metalloproteinase-2 and its density in men with prostate cancer as a new predictor of disease extension. Int J Cancer 1998;79(1):96-101.

28. Groblewska M, Mroczko B, Gryko M, Kędra B, Szmitkowski M. Matrix metalloproteinase 2 and tissue inhibitor of matrix metalloproteinases 2 in the diagnosis of colorectal adenoma and cancer patients. Folia Histochem Cytobiol 2010;48(4):564-71.

29. Karapanagiotidis GT, Antonitsis P, Charokopos N, Foroulis CN Anastasiadis K, Rouska E, Argiriadou H, Rammos K, Papakonstantinou C. Serum levels of matrix metalloproteinases $-1,-2,-3$ and -9 in thoracic aortic diseases and acute myocardial ischemia. J Cardiothorac Surg 2009;4:59.

30. Patel S, Sumitra G, Koner BC, Saxena A. Role of serum matrix metalloproteinase-2 and -9 to predict breast cancer progression. Clin Biochem 2011;44(10-11):869-72.

31. Sheen-Chen S-M, Chen H-S, Eng H-L, Sheen C-C, Chen W-J. Serum levels of matrix metalloproteinase 2 in patients with breast cancer Cancer Lett 2001;173(1):79-82.

32. Vucemilo T, Skoko M, Sarcević B, Puljiz M, Alvir I, Turudić TP, Mihaljević
I. The level of serum pro-matrix metalloproteinase-2 as a prognostic factor in patients with invasive ductal breast cancer. Coll Antropol 2014;38(1):135-40.

33. Heidenreich A, Aus G, Bolla M, Joniau S, Matveev VB, Schmid HP, Zattoni F. EAU guidelines on prostate cancer. Eur Urol 2008;53(1):6880.

34. Zieglschmid V, Hollmann C, Gutierrez B, Krehan A, Kaul S, Böcher O. Heterogeneous expression of tumor-associated genes in disseminated breast cancer cells. Anticancer Res 2007;27(4A):1769-76.

35. Van der Auwera I, Peeters D, Benoy IH, Elst HJ, Van Laere SJ, Prové A, Maes $H$, Huget $P$, van Dam P, Vermeulen PB, Dirix LY. Circulating tumour cell detection: a direct comparison between the CellSearch System, the AdnaTest and CK-19/mammaglobin RT-PCR in patients with metastatic breast cancer. Br J Cancer 2010;102(2):276-84.

36. Mendes O, Kim H-T, Stoica G. Expression of MMP2, MMP9 and MMP3 in breast cancer brain metastasis in a rat model. Clin Exp Metastasis 2005;22(3):237-46.

37. Saito N, Hatori T, Murata N, Zhang Z, Ishikawa F, Nonaka H, Iwabuchi $\mathrm{S}$, Samejima $\mathrm{H}$. A double three-step theory of brain metastasis in mice: the role of the pia mater and matrix metalloproteinases. Neuropathol Appl Neurobiol 2007;33(3):288-98.

38. Feng S, Cen J, Huang Y, Shen H, Yao L, Wang Y, Chen Z. Matrix metalloproteinase- 2 and -9 secreted by leukemic cells increase the permeability of blood-brain barrier by disrupting tight junction proteins. PLoS One 2011;6(8):e20599.

39. De Giorgi U, Valero V, Rohren E, Mego M, Doyle G V, Miller MC, Ueno NT, Handy BC, Reuben JM, Macapinlac H a, Hortobagyi GN, Cristofanilli M. Circulating tumor cells and bone metastases as detected by FDG-PET/CT in patients with metastatic breast cancer. Ann Oncol 2010;21(1):33-9.

40. Duque JL, Loughlin KR, Adam RM, Kantoff PW, Zurakowski D, Freeman MR. Plasma levels of vascular endothelial growth factor are increased in patients with metastatic prostate cancer. Urology 1999;54(3):523-7.

41. Tayebjee MH, Lip GYH, Blann AD, Macfadyen RJ. Effects of age, gender, ethnicity, diurnal variation and exercise on circulating levels of matrix metalloproteinases (MMP)-2 and -9, and their inhibitors, tissue inhibitors of matrix metalloproteinases (TIMP)-1 and -2 . Thromb Res 2005;115(3):205-10.

42. Larsson A, Sköldenberg E, Ericson H. Serum and plasma levels of FGF-2 and VEGF in healthy blood donors. Angiogenesis 2002;5(12):107-10. 